\title{
PERENCANAAN PONDASI TIANG PANCANG PADA GEDUNG SEKRETARIAT DEWAN DPRD KABUPATEN KEDIRI
}

\author{
${ }^{1 *}$ Dwi Hartanto, ${ }^{2}$ Yosef Cahyo S, ${ }^{3}$ Sigit Winarto, ${ }^{4}$ Agata Iwan Candra \\ Fakultas Teknik Universitas Kadiri \\ email: ${ }^{1 *}$ dwi_hartanto@gmail.com, ${ }^{2}$ yosef.cs@unik-kediri.ac.id, ${ }^{3}$ sigit.winarto@unik- \\ kediri.ac.id, ${ }^{4}$ iwan_candra@unik-kediri.ac.id
}

\begin{abstract}
The foundation plays a very important role in the construction of a building. In addition as a foundation for the strength of a building construction, the foundation has the role of distributing the burden of the building on it, so that it can be channeled to the soil underneath it well and make the building able to stand firmly. The purpose of this study is to plan the carrying capacity and size and staking of the Kediri DPRD Council Secretariat Building with sondir data. The author uses the method of direct inspection in the field and coordinates with the Planning Consultant and seeks references from several literatures. From the calculation results obtained the total load of life and death on each floor is $684558.8 \mathrm{Kg}$, $701838.8 \mathrm{Kg}, 736398.8 \mathrm{Kg}$, $736398.8 \mathrm{Kg}$, total loading (Wt) obtained $2806395.4 \mathrm{Kg}$, Dimension of pile foundation $=40 \mathrm{~cm}$; depth $=10$ meters, with the number of two pieces per Pile Cap, the need for reinforcement on the building foundation is $20575.05 \mathrm{Kg}$.
\end{abstract}

Keywords $\quad$ : Pile, Pile Cap, CPT, Bearing Capacity

\begin{abstract}
Abstrak
Pondasi memegang peran yang sangat penting pada konstruksi suatu bangunan.Selain sebagai pijakan kekuatan berdirinya suatu konstruksi bangunan, pondasi berperan mendistribusikan beban bangunan diatasnya, sehingga bisa disalurkan ke lapisan tanah dibawahnya dengan baik dan membuat bangunan mampu berdiri dengan kokoh. Tujuan dari studi ini adalah untuk merencanakan daya dukung serta ukuran dan penulangantiang pancang pada Gedung Sekretariat Dewan DPRD Kabupaten Kediri dengan data sondir. Penulis melakukan metode pemeriksaaan langsung dilapangan serta berkoordinasi dengan pihak Konsultan Perencana dan mencari referensi dari beberapa literatur. Dari hasil perhitungan didapatkan hasil total beban hidup dan mati pada setiap lantai adalah $684558,8 \mathrm{Kg}, 701838,8 \mathrm{Kg}, 736398,8 \mathrm{Kg}$, $736398,8 \mathrm{Kg}$, total Pembebanan (Wt) diperoleh 2806395,4 Kg, Dimensi pondasi tiang pancang $=40 \mathrm{~cm}$; kedalaman = 10 meter, dengan jumlah dua buah per Pile Cap, kebutuhan tulangan pada pondasi gedung adalah $20575.05 \mathrm{Kg}$.
\end{abstract}

Kata Kunci : Tiang Pancang, Pile Cap, CPT, Daya Dukung 


\section{PENDAHULUAN}

Dalam pekerjaan yang berkaitan dengan konstruksi bangunan sipil, pondasi memegang peran utama untuk menahan dan menopang beban bangunan diatasnya beserta bebannya sendiri untuk disalurkan ke lapisan tanah dibawahnya[1][2][3]. Pondasi merupakan bagian yang sangat penting, karena terletak pada bagian bawah dari struktur bangunan yang berfungsi memikul beban-beban, antara lain: beban hidup, beban bangunan sendiri, beban gempa dan lain-lain [4][5] Secara umum penulis mencoba memfokuskan studi pada perencanaan pondasi tiang pondasi pancang, suatu pondasi yang mampu menahan beban dan meyalurkannya ke sumbu tiang dengan jalan menyerap lenturan [6][7]. Pondasi adalah suatu konstruksi pada bagian dasar bangunan (sub-structure) yang berfungsi meneruskan beban dari bagian atas struktur bangunan (upper-structure) ke lapisan tanah yang berada di bagian bawahnya tanpa mengakibatkan keruntuhan geser tanah, dan penurunan (settlement) tanah / pondasi yang berlebihan [8][9][10]. Tiang pancang direkayasa menjadi satu kesatuan monolit yang menyatukan pangkal tiang pancang yang berada dibawah konstruksi dengan tumpuan pondasi, sehingga mampu menyalurkan beban konstruksi diatasnya dan mendistribusikannya ke lapisan tanah yang relatif lebih keras serta mempunyai kekuatan daya dukung yang baik [11][10]. Agar tiang pancang mampu memikul beban diatasnya dengan baik dan bisa memberikan keamanan dan kestabilan pada konstruksi bangunan, perlu memperhitungkan sifat dan daya dukung tanah [12][13][14]. Hal tersebut dapat diketahui dengan melakukan penyelidikan dilapangan serta melakukan penyondiran [15][7].

\section{METODE PENELITIAN}

\subsection{Tes Sondir Tanah}

Cara untuk mengetahui daya dukung tanah, salah satunya adalah dengan melakukanTes sondir atau disebut juga Cone Penetration Test (CPT) [16][17]. Tes ini dilakukan dengan cara mendorong konus (alat berbentuk kerucut) kedalam tanah, kemudian setelah itu akan terjadi perlawanan tanah kepada ujung konus, selanjutnya lekatan tanah pada selimut batang konus tersebut dilakukan pengukuran untuk mendapatkan nilai perlawanan konus (qc) dan gesekan selimut (fs) [18][19][20][21].

\subsection{Data Teknis Perencanaan}

Bangunan Gedung 4 lantai

Gedung di bangun di Kediri, Jawa Timur

$\begin{array}{lll}\text { Panjang bangunan } \mathrm{p} & =22 \mathrm{~m} \\ \text { Lebar bangunan } 1 & =20 \quad \mathrm{~m}\end{array}$


Tinggi lantai $b$

Berat Bangunan Lantai 4

Berat Bangunan Lantai 3

Berat Bangunan Lantai 2

Berat Bangunan Lantai 1

Berat Total Bangunan

Jumlah Kolom

Berat Beban per-Kolom (Pu)

Diameter Tiang Rencana

Kedalaman Tiang Rencana

Berdasarkan Data Sondir didapat :

$$
\begin{aligned}
= & 4,8 \mathrm{~m} \\
& 684,55 \text { Ton } \\
& 701,83 \text { Ton } \\
& 736,39 \text { Ton } \\
& 736,39 \text { Ton }+ \\
& 2859,19 \text { Ton } \\
= & 20 \text { buah } \\
= & 140,32 \text { Ton } \\
= & 40 \mathrm{~cm} \\
= & 10 \text { meter }
\end{aligned}
$$

Tabel 1. Hasil Sondir Sepanjang 4D Bagian Atas Rencana Ujung Tiangdan 1D Dibawah Ujung Tiang

\begin{tabular}{|c|c|c|c|c|c|c|c|}
\hline \multirow{2}{*}{ Kedalaman } & Bacaan & Bacaan & Nilai & Lekatan & \multirow{2}{*}{ HL } & \multirow{2}{*}{ JHL } & FRICTI0N \\
\cline { 2 - 5 } & 1 & 2 & Konus & Lokal & & & RATI0 \\
\hline (m) & $\mathrm{Kg} / \mathrm{cm} 2$ & $\mathrm{Kg} / \mathrm{cm} 2$ & $\mathrm{Kg} / \mathrm{cm} 2$ & $\mathrm{Kg} / \mathrm{cm} 2$ & $\mathrm{Kg} / \mathrm{cm}$ & $\mathrm{Kg} / \mathrm{cm}$ & $\%$ \\
\hline \hline 8,4 & 45 & 55 & 45 & 10 & 20 & 840 & 2,2 \\
\hline 8,6 & 50 & 60 & 50 & 10 & 20 & 880 & 2 \\
\hline 8,8 & 55 & 65 & 55 & 10 & 20 & 880 & 1,8 \\
\hline 9 & 60 & 70 & 60 & 10 & 20 & 900 & 1,7 \\
\hline 9,2 & 75 & 90 & 75 & 15 & 30 & 930 & 2 \\
\hline 9,4 & 80 & 95 & 80 & 15 & 30 & 960 & 1,9 \\
\hline 9,6 & 100 & 115 & 100 & 15 & 30 & 990 & 1,5 \\
\hline 9,8 & 135 & 150 & 135 & 15 & 30 & 1020 & 1,1 \\
\hline 10 & 150 & 170 & 150 & 20 & 40 & 1060 & 1,3 \\
\hline 10,2 & 165 & 185 & 165 & 20 & 40 & 1100 & 1,2 \\
\hline 10,4 & 160 & 200 & 160 & 40 & 80 & 1140 & 1,1 \\
\hline & & & & & & & \\
\hline
\end{tabular}




\section{PEMBAHASAN}

\subsection{Perhitungan Kapasitas Ijin Tiang (Qall)}

Metode Meyerhof (1956) :

$$
\begin{aligned}
& \text { Qult }=q c_{r} \cdot A_{p}+\sum f s \cdot A_{s} \\
& \text { Qall }=\frac{\text { Qult }}{F K}
\end{aligned}
$$

Dimana :

$$
\begin{array}{ll}
\text { Qult } & \text { = beban maksimum } \\
\text { Qall } & \text { = kapasitas beban yang diijinkan } \\
\text { Ap } & \text { = luas penampang dasar pondasi tiang } \\
\text { As } & \text { = keliling pondasi tiang } \\
\text { qcr } & \text { = qc rata-rata, sepanjang 4D bagian atas rencana ujung }
\end{array}
$$

tiangdan 1D dibawah ujung tiang

$$
\begin{array}{ll}
\Sigma \mathrm{fs} & =\text { jumlah hambatan lekat } \\
\text { FK } & =\text { factor keamanan nilainya antara } 2,5 \mathrm{~s} / \mathrm{d} 3, \text { diambil }
\end{array}
$$

sebesar 2,5

(Sumber : Jurnal Studi Analisis Daya Dukung Pondasi Tiang)

Maka didapat :

$$
\begin{array}{ll}
\text { Ap } & =3,14 \times 0,2 \times 0,2=0,1256 \mathrm{~m} 2 \\
\text { As } & =2 \times 3,14 \times 0,2=1,25 \mathrm{~m} \\
\text { qcr } & =(45+50+55+60+75+80+100+135+150+165+180) \\
& =99,54 \mathrm{Kg} / \mathrm{cm} 2=995,4 \mathrm{Ton} / \mathrm{m} 2 \\
\Sigma \text { fs } & =1060 \mathrm{Kg} / \mathrm{cm}=106 \mathrm{Ton} / \mathrm{m} \\
\text { FK } & =2,5 \\
\text { Qult }=995,4 & 0,1256+106.1,25=257,52 \text { Ton } \\
\text { Qall }=257,52 & \text { Ton }: 2,5=103,01 \text { Ton }
\end{array}
$$

\subsection{Kebutuhan Jumlah Tiang}

Tabel 4.6 Kebutuhan Jumlah Tiang Pancang

\begin{tabular}{|c|c|c|}
\hline $\begin{array}{c}\text { Beban } \\
(\mathrm{Pu})\end{array}$ & $\begin{array}{c}\text { Daya Dukung Ijin } \\
(\text { Qall })\end{array}$ & $\begin{array}{c}\text { Jumlah Tiang } \\
(\mathrm{N}=\mathrm{Pu} / \text { Qall })\end{array}$ \\
\hline 140,32 Ton & 103,01 Ton & 1,36 \\
\hline
\end{tabular}

(dibulatkan $=2$ buah)

Maka pondasi memakai 2 buah tiang 


\subsection{Perhitungan Efisiensi Tiang}

Diameter Tiang

$$
\mathrm{d}=0,4 \quad \mathrm{~m}
$$

Jarak antar tiang

$$
\mathrm{s}=3 \mathrm{~d}=1,2 \mathrm{~m}
$$

Jumlah dalam baris

$$
\mathrm{m}=1
$$

Jumlah dalam kolom

$\mathrm{n}=2$ buah

$\theta=\arctan \mathrm{d} / \mathrm{s}=18,26$

$\mathrm{Eg}=1-\theta \times(((m-1) \times n+(n-1) \times m) /(90 \times m \times n))=0,898$

\subsection{Daya Dukung Tiang}

Beban Ultimite

$$
\begin{aligned}
\mathrm{Pu} & =140,32 \text { Ton } \\
\mathrm{n} & =2 \text { buah } \\
\mathrm{Eg} & =0,898 \\
\text { Qall } & =103,01 \text { Ton }
\end{aligned}
$$

Jumlah Tiang

Efisiensi grup tiang

Daya dukung ijin

Daya dukung tiang tunggal

$$
\text { Qug = Qall x n x Eg = 185,00 Ton }
$$

$$
\mathrm{Pu} \leq \text { Qug } \rightarrow \quad \text { (AMAN) }
$$

Dapat disimpulkan nilai Pu dan Qug untuk pondasi yaitu :

Tabel 2. Hasil Daya Dukung Tiang

\begin{tabular}{|c|c|c|}
\hline Tipe Pondasi & $\begin{array}{c}\text { Beban Ultimit } \\
\mathrm{Pu}\end{array}$ & \\
\hline $\mathrm{P} 1$ & 140,32 Ton & 185,00 Ton \\
\hline
\end{tabular}

\subsection{Jumlah Kebutuhan Tulangan Pondasi}

Tulangan Pondasi Bored Pile

Tulangan Utama 16 - D22
a) Berat Jenis Besi D22 per-meter : $2.98 \mathrm{Kg}$
b) Jumlah Penulangan per unit: 16
c) Jumlah Bored Pile : 40
d) Total Panjang penulangan /unit $: 8,4 \mathrm{~m}$

Oversteek Sambungan/unit

$$
=40 \times \mathrm{D}=40 \times 22=880 \mathrm{~mm} \quad: 0.88 \mathrm{~m}
$$

Total panjang penulangan/unit $\quad:(8.4+0.88) \times 16=148.48 \mathrm{~m}$

e) Jumlah Kebutuhan Tul. Utama :

$148.48 \times 40 \times 2.98=17698.81 \mathrm{Kg}$

Tulangan Geser $\varnothing 12$ - 250 
f) Berat Jenis Besi $\varnothing 12$ per-meter $\quad: 0.890 \mathrm{Kg}$

g) Diamter Tulangan Geser $\quad: 0.30 \mathrm{~m}$

h) Jumlah Tul. Geser per pile : 34

i) Jumlah Bored Pile : 40

j) Total Panjang penulangan /unit $: 2 \square \square \mathrm{r}=2 \times 3.14 \times 0.15=0.942 \mathrm{~m}$

k) Kait Tulangan Geser

6 x Diameter Tul. $=6 \times 0.012=0.072 \mathrm{~m} \mathrm{x} 2$ buah/tulangan geser $=0.144 \mathrm{~m}$

1) Jumlah Kebutuhan Tul. Geser :

$(0.942+0.144) \times 34 \times 40 \times 0.890 \mathrm{Kg}=1314.49 \mathrm{Kg}$

Tulangan Pile Cap D22 - 200

m) Berat Jenis Besi D22 per-meter $\quad: 2.98 \mathrm{Kg}$

n) Jumlah Pile Cap :20 buah

o) Lebar Penulangan arah $\mathrm{x} \quad: 1.60-0.05=1.55 \mathrm{~m}$

p) Lebar Penulangan arah y $\quad: 0.60-0.05=0.55 \mathrm{~m}$

q) Selimut BeTon : $0.05 \mathrm{~m}$

r) Jumlah Penulangan arah $\mathrm{x} \quad: 1.60 / 0.20=8$ buah

s) Jumlah Penulangan arah y $\quad: 0.60 / 0.20=3$ buah

t) Total Panjang penulangan /unit :

Arah $\mathrm{x}=(1.55+1.55+0.20+0.20) \times 3=10.5 \mathrm{~m}$

Arah y $=(0.60+1.60+0.20+0.20) \times 8=12.8 \mathrm{~m}$

Kait Tulangan Arah x

$6 \times$ Diameter Tul. $=6 \times 0.022=0.072 \mathrm{~m} \times 2$ buah/tulangan

$=0.264 \mathrm{mx} 11$ (jumlah penulangan arah $\mathrm{x}$ dan $\mathrm{y}$ )

$=2.904 \mathrm{~m}$

Total Panjang penulangan/unit

$10.5+12.8+2.904=26.204 \mathrm{~m}$

u) Total Kebutuhan Tulangan Pile Cap:

Total panjang Tul. x Jumlah Pile Cap x Berat Jenis Besi

$=26.204 \mathrm{~m}$ x 20 buah $\times 2.98 \mathrm{Kg} / \mathrm{m}=1561.75 \mathrm{Kg}$

Jumlah Tulangan Pondasi

Tulangan Utama Bored Pile 16 - D22 = $17698.81 \mathrm{Kg}$

Tulangan Geser Bored Pile Ø12-250 = $\quad 1314.49 \mathrm{Kg}$

Tulangan Pile Cap D22 - $200 \quad=\quad 1561.75 \mathrm{Kg}+$

Jumlah Tulangan Pondasi $=20575.05 \mathrm{Kg}$ 


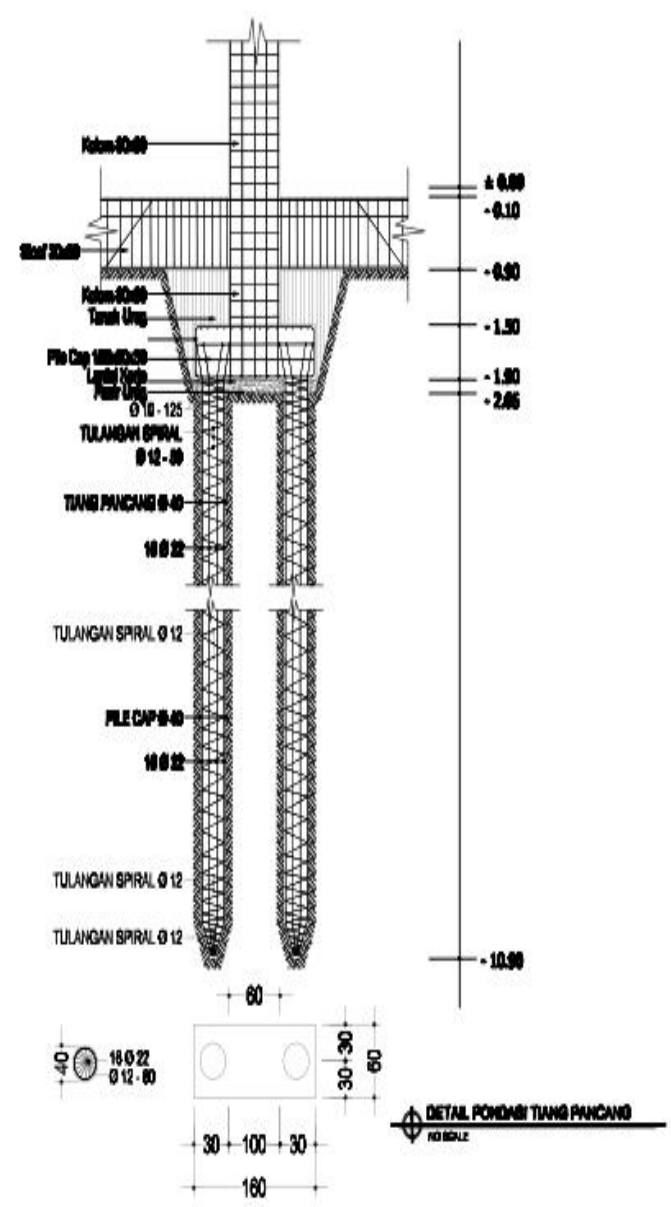

Gambar 1. Detail Pondasi Tiang Pancang

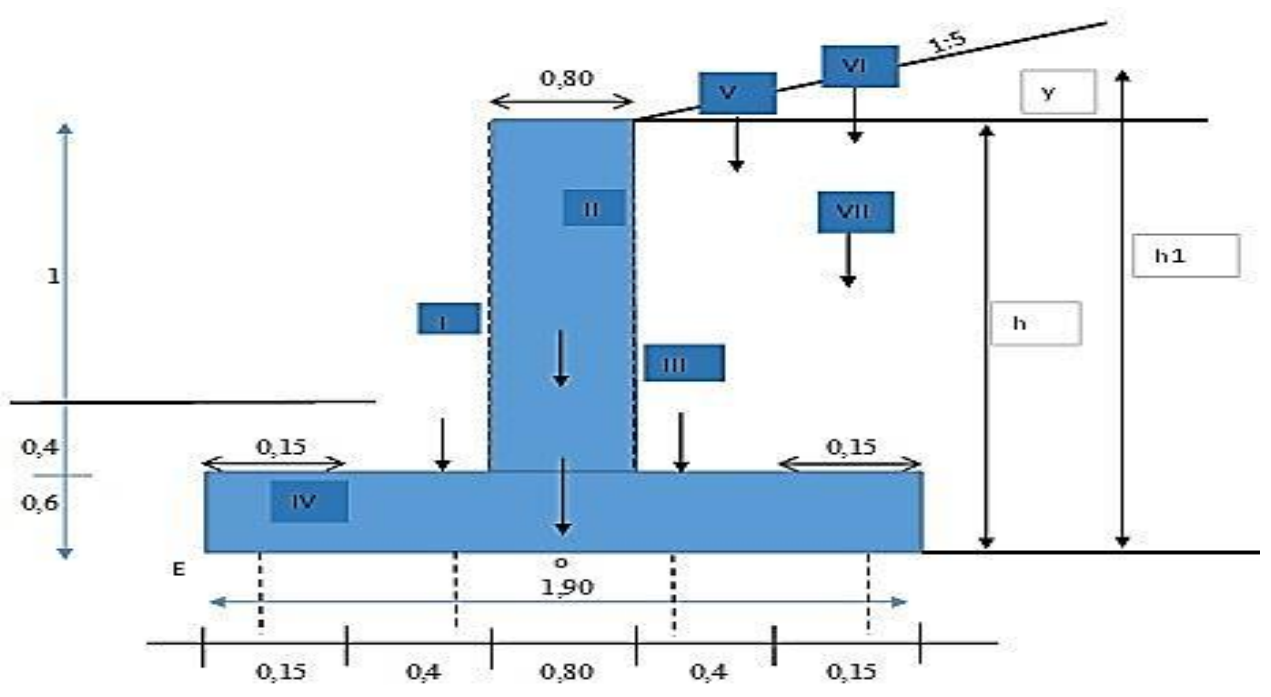




\section{Cek Guling}

$\mathrm{n}=\mathrm{MP} / \mathrm{MG} 9,176 \mathrm{t} / \mathrm{m} 2 \gg>1,5 \mathrm{t} / \mathrm{m} 2$

Cek Geser

$\mathrm{n}=\Sigma \mathrm{W} / \Sigma \mathrm{E} 6,221 \mathrm{t} / \mathrm{m} 2>>>1,5 \mathrm{t} / \mathrm{m} 2$

maka AMAN

Penurunan Kekuatan Tumit

Terhadap Geser

$0,0953 \mathrm{t} / \mathrm{m} 2 \gg>15 \mathrm{t} / \mathrm{m} 2$

maka AMAN

Terhadap Tarik

$0,0508 \mathrm{t} / \mathrm{m} 2 \gg>30 \mathrm{t} / \mathrm{m} 2$

maka AMAN

Penurunan Kekuatan Kaki

Terhadap Geser

$0,8279 \mathrm{t} / \mathrm{m} 2 \gg>15 \mathrm{t} / \mathrm{m} 2$

maka AMAN

Terhadap Tarik

$0,4156 \mathrm{t} / \mathrm{m} 2 ~ \gg>30 \mathrm{t} / \mathrm{m} 2$

maka AMAN

Penurunan Kekuatan Badan

б.max $2,7480 \mathrm{t} / \mathrm{m} 2 \gg>150 \mathrm{t} / \mathrm{m} 2$

maka AMAN

$\sigma . \min 2,9209 \mathrm{t} / \mathrm{m} 2>>>300 \mathrm{t} / \mathrm{m} 2$

maka AMAN

\section{KESIMPULAN DAN SARAN}

\subsection{Kesimpulan}

Berdasarkan perencanaan pondasi tiang pancang pada Gedung Sekretariat Dewan DPRD Kabupaten Kediri dapat disimpulkan sebagai berikut:

1. Pembebanan yang terjadi pada gedung lantai satu sampai empat adalah :
a) Beban hidup dan beban mati lantai 4 diperoleh sebesar $684558,8 \mathrm{Kg}$
b) Beban hidup dan beban mati lantai 3diperoleh sebesar 701838,8 Kg
c) Beban hidup dan beban mati lantai 2diperoleh sebesar $736398,8 \mathrm{Kg}$
d) Beban hidup dan beban mati lantai 1diperoleh sebesar $736398,8 \mathrm{Kg}$
e) Maka, total Pembebanan (Wt)diperoleh 2806395,4 Kg = 2859,19 Ton

2. Dimensi Tiang Pancang $=40 \mathrm{~cm}$; Kedalaman $=10$ meter. Jumlah dua buah per Pile Cap

3. Tulangan Pondasi Tiang Pancang yang dipakai menggunakan besi diameter $22 \mathrm{~mm}$, jarak 200mm, jumlah besi per pile cap 16 buah, dengan total tulangan yang diperlukan $30.088,80 \mathrm{Kg}$ 


\subsection{Saran}

1. Perencanaan pondasi tidak hanya berpedoman pada ilmu tetapi dipertimbangkan pula pada pedoman yang biasa dilaksanakan di lapangan.

2. Untuk mendapat hasil yang akurat, maka dibutuhkan pemahaman yang menyeluruh tentang tahap - tahap dalam proses perencanaan, dan teori - teori yang didapat di bangku kuliah harus selalu dikembangkan.

\section{UCAPAN TERIMAKASIH}

Dalam penyusunan artikel ini, penulis ucapkan terimakasih kepada dosen pembimbing dan Universitas Kadiri. Penulis berharap agar artikel ini dapat bermanfaat bagi pembaca.

\section{DAFTAR PUSTAKA}

[1] A. S. N. SAPUTRA, G. WIRATAMA, and I. MUHAMMAD, "PERENCANAAN GEDUNG D KAMPUS IV UNIVERSITAS MUHAMMADIYAH BENGKULU.” POLITEKNIK NEGERI SRIWIJAYA, 2016.

[2] D. A. Andhira, "PERENCANAAN PERHITUNGAN PLAT LANTAI, BALOK DAN KOLOM PADA GEDUNG BERLANTAI III.” undip, 2017.

[3] B. S. Nasional, "Tata cara perencanaan ketahanan gempa untuk struktur bangunan gedung dan non gedung," Sni, vol. 1726, p. 2012, 2012.

[4] A. I. Candra, "Pada Pembangunan Gedung Mini Hospital Universitas Kadiri," Ukarst, vol. 1, no. 1, pp. 63-70, 2017.

[5] A. Pamungkas and E. Harianti, "Desain Pondasi Tahan Gempa Sesuai SNI03-1726-2002 dan SNI 03-2847-2002,” 2002.

[6] I. I. M. Sudarma, I. B. Indramanik, and A. . P. A. Putra, "ANALISA PERBANDINGAN PERENCANAAN STRUKTUR ANTARA PONDASI BORE PILE DENGAN PONDASI TIANG PANCANG (STUDI KASUS PADA PROYEK GEDUNG DPRD BALI)," pp. 15-30, 2015.

[7] S. - 1726- 2002, "STANDAR PERENCANAAN KETAHANAN GEMPA UNTUK STRUKTUR BANGUNAN GEDUNG,” vol. 7798393, no. April, 2002.

[8] F. Febriantoro, Y. C. S. Purnomo, and A. Ridwan, "Study Perencanaan Pondasi Tiang Pancang Jembatan Sembayat Baru II Kecamatan Manyar Kabupaten Gresik,” J. Manaj. Teknol. Tek. Sipil, vol. 1, no. 1, pp. 148-159, 2018, doi: 10.30737/jurmateks.v1i1.147.

[9] A. I. Candra, A. Yusuf, and A. R. F, "Studi Analisis Daya Dukung Pondasi Tiang Pada Pembangunan Gedung Lp3m Universitas Kadiri,” CIVILLa, vol. 3, no. 2, pp. 166-171, 
2018.

[10] direktorat penyelidikan masalah Bangunan, "peraturan-pembebanan-indonesia1983.pdf." .

[11] H. C. Hardiyatmo, "Analisa dan Perancangan Fondasi bagian 1." Gadjah Mada University Press, Jogjakarta, 2010.

[12] P. Anugrah and H. Erny, "Desain Pondasi Tahan Gempa Sesuai SNI 03-1726-2002 dan SNI 03-2847-2002," Andi, Yogyakarta, 2013.

[13] D. P. Umum, "Standar Tata Cara Perhitungan Struktur Beton untuk Bangunan Gedung," SK SNI T-15-1991-03, Yayasan LPBM, Bandung, 1991.

[14] A. A. P. A. Putra, I. B. G. Indramanik, and I. M. Sudarma, "ANALISA PERBANDINGAN PERENCANAAN STRUKTUR ANTARA PONDASI BORE PILE DENGAN PONDASI TIANG PANCANG," J. Tek. Gradien, vol. 8, no. 2, pp. 15-30, 2016.

[15] A. Aminudin and N. Z. Devi, "ANALISIS DAYA DUKUNG PONDASI BORED PILE PADA PROYEK PEMBANGUNAN JALAN TOL BAWEN-SALATIGA PAKET 3.1.” Fakultas Teknik UNISSULA, 2016.

[16] F. Haliq, "Islam Madura: Studi Konflik, Adaptasi, Harmoni Kelas Menengah Madura Setelah Keruntuhan Orde Baru,” 2010.

[17] E. Bowles Joseph, “Analisa dan Desain Pondasi jilid 1," Penerbit Erlangga, Jakarta.(23 Februari 2019), 1986.

[18] A. Soenaryo, M. T. Hidayat, and H. Siswanto, "Perbaikan Kolom Beton Bertulang Menggunakan Concrete Jacketing dengan Prosentase Beban Runtuh yang Bervariasi,” Rekayasa Sipil, vol. 3, no. 2, pp. 91-100, 2012.

[19] C.-K. Wang, B. Hariandja, and C. G. Salmon, Desain beton bertulang. Erlangga, Jakarta, 1987.

[20] W. Hadi Pratomo, "Struktur Beton Prategang (Teori dan Prinsip Desain)," Nova, 1994.

[21] M. B. Hanafi, "Perencanaan Struktur Apartemen 5 Lantai+ 1 Basement Dengan Sistem Rangka Pemikul Momen Menengah (SRPMM) Di Sukoharjo.” Universitas Muhammadiyah Surakarta, 2015. 